\title{
Research Progress on the Effect of Number of Stent Retriever Passes on the Outcome of Endovascular Treatment of Acute Ischemic Stroke
}

\author{
Shijie Yang1, Huan Xi1, Erqing Chai2* \\ ${ }^{1}$ The First Clinical Medical College of Gansu University of Chinese Medicine (Gansu Provincial Hospital), Gansu University of \\ Chinese Medicine, Lanzhou, China \\ ${ }^{2}$ Key Laboratory of Cerebrovascular Disease of Gansu Province, Gansu Provincial Hospital, Lanzhou China \\ Email: *happybirds998@126.com
}

How to cite this paper: Yang, S.J., Xi, H. and Chai, E.Q. (2022) Research Progress on the Effect of Number of Stent Retriever Passes on the Outcome of Endovascular Treatment of Acute Ischemic Stroke. Journal of Biosciences and Medicines, 10, 98-110. https://doi.org/10.4236/jbm.2022.102010

Received: December 29, 2021

Accepted: February 18, 2022

Published: February 21, 2022

Copyright $\odot 2022$ by author(s) and Scientific Research Publishing Inc. This work is licensed under the Creative Commons Attribution International License (CC BY 4.0).

http://creativecommons.org/licenses/by/4.0/ (c) (i) Open Access

\begin{abstract}
Introduction: Endovascular treatment is an effective treatment for large vessel occlusive ischemic stroke. The number of Stent Retriever passes is an important link in the strategy of endovascular treatment, and is closely related to the clinical outcome and prognosis of patients with acute ischemic stroke, but there is still a lack of unified understanding. In order to provide reference for clinical practice and related research, this paper reviewed the recent important literatures. Methods: We searched PubMed, Embase, and Cochrane databases, using the terms "stents", "stroke" and "thrombectomy". Priority was given to human studies. Only English language papers were accepted. Analyze the articles by title and abstract. Results: The number of Stent Retriever passes is closely related to the rate of recanalization, hemorrhagic transformation, recanalization time, surgical procedures and clinical prognosis. Along with the increase of the number of Stent Retriever passes, the vascular recanculation rate decreased successively, in turn, reduced the rate of blood vessels, 3 times may be the target vascular occlusion which should try the best of times, $\geq 4$ times may not improve the opportunity of recanalization and not conducive to the prognosis, at the same time, increase the risk of HT and related complications occurred. Conclusion: It is necessary to avoid unplanned, additional attempts at EVT. The number of Stent Retriever passes has significant effects on the outcome of EVT of AIS in many aspects. How to better personalized EVT strategy is the focus of future research.
\end{abstract}




\section{Keywords}

Stents, Ischemic Stroke, Thrombectomy, Endovascular Procedures

\section{Introduction}

The burden of stroke in low- and middle-income countries is higher than in high-income countries and is rising [1]. Endovascular treatment (EVT) is an effective treatment for acute ischemic stroke (AIS) caused by large vessel occlusion (LVO). Relevant studies have confirmed that EVT can bring significant clinical benefits for patients with anterior circulation LVO stroke [2] [3] [4]. With the further promotion and popularization of EVT in clinical application, it has been found that EVT has considerable benefits on the functional prognosis of AIS, but about $50 \%$ of the patients died or were still dependent after 3 months [5]. These adverse results may not be solely attributable to unsuccessful recanalization, as approximately one third of patients who achieve early complete recanalization even after EVT does not have ideal results [6]. The occurrence of this situation may be a problem of patient screening, or may be related to the EVT procedures [7].

Related studies have reported that the number of Stent Retriever passes is closely related to the clinical outcome and prognosis of patients with AIS [2] [3] [4]. However, due to the large individual differences of patients, many influencing factors, and the differences in therapeutic concepts and practices among clinicians, there is still a lack of unified understanding at present. This paper reviews and summarizes the relevant guidelines and studies, in order to provide reference for clinical practice and later related research.

\section{Materials and Methods}

We searched PubMed, Embase, and Cochrane databases for the terms "stents", "stroke" and "thrombectomy". A total of 244 records were found, and 30 records remained after removing duplicate and unrelated documents. After careful review of the title, abstract, and full text, 11 articles were deleted as follows: 1) thrombolytic exclusion, $(n=6), 2)$ unevaluated related results $(n=4)$, and 3 ) edited $(n=1)$. Nineteen articles were included (Figure 1 , Table 1 ).

\section{Results}

\subsection{The Relationship between the Number of Stent Retriever Passes and the Rate of Vascular Successful Recanalization}

In recent years, it has been found in clinical practice that unplanned continuous EVT attempts have not significantly increased the rate of vascular successful recanalization or degree of recanalization.

Garcia-Tornel A et al. found in a single-center retrospective study that the vascular recanalization rates of the first to fourthStent Retrieverpasses were $39 \%$ 


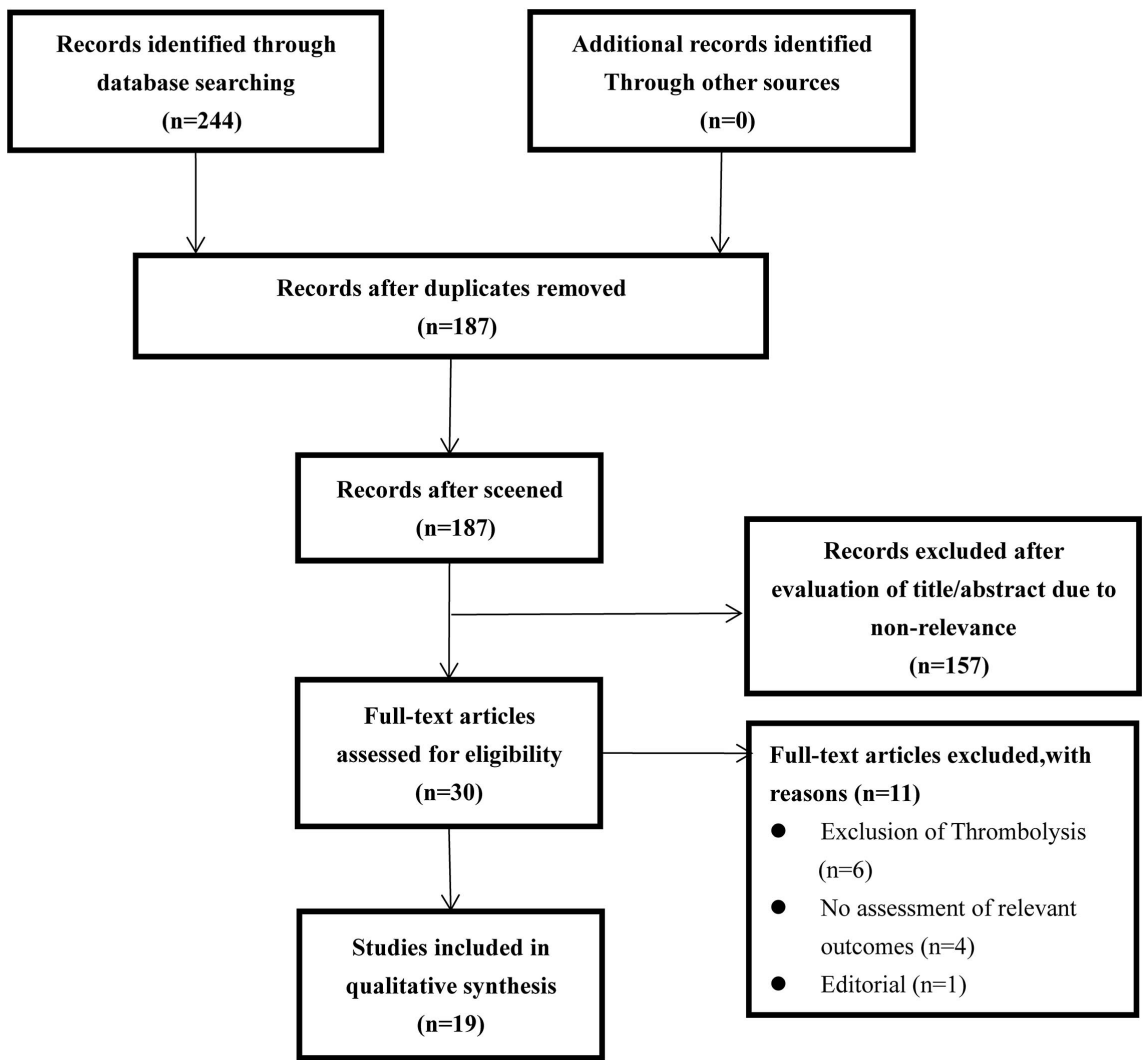

Figure 1. Flow chart of literature search and selection.

Table 1. Characteristics of included studies.

\begin{tabular}{ccccc}
\hline Author & Year & Population Number of cases & research characteristic \\
\hline García-Tornel Á & 2019 & Spain & 704 & Retrospective single-center \\
Filioglo A & 2020 & Israel & 271 & Retrospective single-center \\
Kharouba R & 2019 & Israel & 96 & Retrospective single-center \\
Baek J & 2018 & Korea & 467 & Retrospective multicenter \\
Flottmann F & 2018 & Germany & 330 & Retrospective single-center \\
LOH Y & 2010 & America & 97 & prospective cohort study \\
Angermaier A & 2016 & Germany & 63 & Retrospective single-center \\
Li W & 2020 & China & 88 & Retrospective single-center \\
Renú A & 2017 & Spain & 146 & Retrospective single-center \\
Kalinin MN & 2017 & Russia & 783 & Retrospective single-center \\
Hao Y & 2017 & China & 632 & Retrospective multicenter \\
Bourcier R & 2019 & France & 281 & prospective cohort study \\
Hassan AE & 2019 & America & 329 & Retrospective single-center \\
Khatri P & 2014 & America & 656 & Retrospective multicenter \\
Kleine JF & 2017 & Germany & 352 & Retrospective single-center \\
Seker F & 2017 & Germany & 104 & Retrospective single-center \\
Tan IYL & 2009 & Canada & 85 & Retrospective single-center \\
Goyal N & 2019 & America & 287 & Retrospective single-center \\
Tonetti DA & 2020 & America & 250 & Retrospective single-center \\
\hline
\end{tabular}


(213/542), 35\% (113/310), 33\% (63/190) and 24\% (26/154), respectively. The vascular recanalization rate was $28 \%(45 / 158)$ in patients with more than 4 Stent Retriever passes $(\mathrm{P}<0.001)$ [7]. A multi-center retrospective study by Jang-Hyun Baek et al. found that as the number of Stent Retriever passes increased, the rate of vascular recanculation in each successive thrombectomy group decreased sequentially, from $45.3 \%$ in the first attempts to $0.3 \%$ in the seventh attempts, and was expected to increase by only 5.5\% after the fifth attempts [8]. Moreover, modified thrombolysis in cerebral infarction score (mTICI) 3 patients were more likely to experience fewer the number of Stent Retriever passes. Two-thirds of the patients achieved successful recanalization during the first 3 Stent Retriever passes [9].

The study of Loh et al. showed that the number of Stent Retriever passes in patients with AIS was not consistently correlated with successful recanalization of vessels. After 3 Stent Retriever passes, each subsequent attempt only produced a very small recanalization of vessels and increased the incidence of complications. At the same time, in the Loh team's experience, 3 Stent Retriever passes may be the optimal number for occlusion of the target vessel, and $\geq 4$ attempts not improve the chance of recanalization and increase the risk of complications [10]. However, according to the study of Angermaier A, 2.5 Stent Retriever passes was the best indicator for the discrimination of successful recanalization (area under the curve [AUC], 0.69; 95\% confidence interval [CI], $0.54-0.84 ; \mathrm{P}=$ 0.02 ), and, in univariate regression analysis, 2 Stent Retriever passes or less was significantly associated with a 4.28 -fold increase in the chance of revascularization [11]. Through the above studies, it is not difficult to find that the more times of Stent Retriever passes, the lower the rate of vascular recanalization, and the increase of vascular recanalization rate is extremely limited when the number of Stent Retriever passes exceeds a certain number.

\subsection{The Relationship between the Number of Stent Retriever Passes and Hemorrhagic Transformation}

Hemorrhagic transformation (HT) is a common and frequent complication for patients undergoing EVT. Several risk factors for HT in AIS have been reported in relevant studies, including atrial fibrillation, diabetes mellitus, congestive heart failure, platelet count, blood glucose level, total cholesterol level, NIHSS score at admission, baseline ASPECTS and surgical related factors [3] [12] [13] [14].

The effect of surgical factors on HT, such as the number of Stent Retriever passes, has not been well established. A study that analyzed 632 patients found that among the patients with HT after EVT, more patients underwent more than 3 Stent Retriever passes [15]. In univariate analysis, compared with patients who underwent $\leq 3$ Stent Retriever passes, patients with $>3$ Stent Retriever passes had significantly more intracranial hemorrhage or parenchymal hematomas [16].

Other studies have found that Stent Retriever causes greater vascular injury than contact aspiration (CA), and has a higher probability of hemorrhagic transformation after multiple aspiration [17] [18]. Romain Bourcier et al. performed 
grouping analysis based on CA vs. Stent Retriever, and found only in the Stent Retriever treatment group, patients with 3 Stent Retriever passes had an increased risk of parenchymal hematoma (PH) (adjusted odds ratio [OR], 9.24; 95\% CI, 2.65 - 32.13) and not found in the CA treatment group (adjusted relative risk [RR], 1.73; 95\% CI, 0.57 - 5.19) [16].

However, Hassan AE et al. found that there was no correlation between the number of Stent Retriever passes and the incidence of HT [19]. Based on the current study, whether there is a correlation between the number of Stent Retriever passes and HT needs to be further verified by higher quality evidence.

\subsection{The Relationship between the Number of Stent Retriever Passes and Procedure Time}

Recanalization is very important, but it is not the only factor affecting the functional outcome. The time from symptom onset to recanalization (SORT) is also an important factor [20]. In patients with successful recanalization, 1 Stent Retriever pass was associated with a shorter (SORT) (238 minutes vs. 280 minutes, $\mathrm{p}<0.001$ ) [21]. Jeffrey L. Saver et al. analyzed 390 patients with substantial recanalization after endovascular thrombectomy and found that each hour of delay in recanalization was associated with poorer disability (common odds ratio [cOR], 0.84 [95\% CI, 0.76 - 0.93]; absolute risk difference [ARD], -6.7\%) and related functional independence (OR, 0.81 ( $95 \% \mathrm{CI}, 0.71$ to 0.92 ); $\mathrm{ARD},-5.2 \%$ [95\% CI, $-8.3 \%--2.1 \%]$ ). For every 9 minute delay in SORT, 1 in 100 treated patients had a more severe disability outcome (a higher modified Rankin Scale [mRS] score of 1 point or higher). The probability of 3-month functional independence (mRS 0 - 2) decreased from $64.1 \%$ for 180 minutes by SORT to $46.1 \%$ for 480 minutes by SORT [22]. In addition, Mazighi $M$ et al. found that every 30 min reduction in SORT resulted in a $20 \%$ reduction in intracranial bleeding [23].

Equally, the time from onset to groin puncture (OTP) is also an important factor. The longer the OTP, the lower the chance of a better disability outcome at 90 days: 3 hours, cOR 2.79 (95\% CI, 1.96 to 3.98), ARD 39.2\%; 6 h, cOR 1.98 ( $95 \% \mathrm{CI} 1.30$ to 3.00 ), $\mathrm{ARD} 30.2 \%$; $8 \mathrm{~h}$, cOR 1.57 (95\% CI 0.86 to 2.88 ), ARD $15.7 \%$. It remained significant for 7 hours and 18 minutes, and the benefit was not significant after 7.3 hours [22]. Hao Y et al. found that the OTP delay was 270 minutes (OR, 1.70; 95\% CI, 1.03, 2.80) was associated with symptomatic intracranial hemorrhage (SICH) after endovascular treatment. The OTP of patients with SICH was longer than that of patients without SICH (median, 307 minutes vs. 269 minutes; $\mathrm{P}=0.035$ ) [15].

Jang-hyun Baek et al. also found that there is a significant linear relationship between the time from groin puncture to recanalization (PTR) value and the times of EVT, each additional Stent Retriever passes increased PTR by $15.9 \mathrm{mi}-$ nutes $(\mathrm{P}<0.001)$. In addition, the sort value increased significantly with the increase of the number of Stent Retriever passes $(\mathrm{P}<0.001)$, however, was much 
weaker than the correlation with the number of PTR $(r=0.170)$. PTR $=125 \mathrm{mi}$ nutes is a cutoff point, associated with invalid reconnects. After 125 minutes of PTR treatment, even if the vessels were recanalized successfully, the patient's functional prognosis was not significantly better than that of patients without recanalization. In multivariate analysis, this cutoff time was also an independent predictor of ineffective recanalization ( $\mathrm{OR}, 1.87$; 95\% CI, $0.556 .31 ; \mathrm{P}=0.313$ ); Similarly, Baek et al. determined a valid OTR cutoff time of 580 minutes for invalid recalculations [8].

In terms of clinical outcomes, the time to successful recanalization of the vessels is an important reference. In addition, the number of Stent Retriever passes can be used as a surrogate marker for surgical time, and successful recanalization of the vessel within 125 minutes of PTR may benefit the patient's ultimate prognosis.

\subsection{The Relationship between the Number of Stent Retriever Passes and Prognosis}

As approximately one third of patients who achieve early complete recanalization even after EVT do not have ideal results [24]. This can be explained by the so-called "ineffective recanalization", i.e., in patients who achieved mTICI $2 \mathrm{~B} / 3$ scores after EVT, after 3 months failure to achieve functional independence (mRS > 2) [25]. Rawan Kharouba et al. found a very significant correlation between the number of Stent Retriever passes and favorable outcomes $(\mathrm{mRS} \leq 2)(\mathrm{P}=0.008)$ [4].

The first pass recanalization (FPR) and degree of recanalization are associated with better clinical outcomes [4] [26]. A number of studies have found that the rate of good outcome in FPR group is higher than that in patients with multiple Stent Retriever passes or with mTICI $2 \mathrm{C} / 3$ achieved by rescue therapy, and successful recanalization of vessels after FPR is still independently associated with good outcome. In addition, in a multivariate analysis, less than 4 Stent Retriever passes were an independent predictor of better outcomes (1 time, OR: 8.06, 95\% CI, 3.69 - 17.6; OR: 7.78, 95\% CI, 3.37 - 18.0; OR 6.10, 95\% CI, 2.31 - 16.1; OR 6.57, 95\% CI, 2.11 - 20.4; P < 0.001) [2] [4] [7] [26]. Another study found that patients with recanalization of vessels after more than 4 Stent Retriever passes had a better prognosis than those without recanalization. However, the functional prognosis of patients with $\geq 5$ Stent Retriever passes and recanalization was not significantly better than that of patients with incomplete recanalization ( 5 times, OR: 1.70, 95\% CI, 0.42 - 6.90, $\mathrm{P}=0.455$; 6 OR higher, OR 0.33, 95\% CI, 0.02 5.70, $\mathrm{P}=0.445$ ) [4] [11] [26].

Patients with fewer than 4 Stent Retriever passes had significantly better outcomes $(52 \%$ vs. $30 \%$; $\mathrm{P}=0.009)$ [3]. Seker $\mathrm{F}$ et al. found that each additional Stent Retriever passes resulted in worse outcomes $(\mathrm{P}<0.01)$, and patients who require only one thrombectomy procedure to obtain mTICI $2 \mathrm{~B}$ or 3 are more likely to have a good outcome than patients who require two or more attempts 
to obtain the same degree of recanalization. In addition, the rate of good outcomes in final mTICI 2B patients began to decline after the 2 Stent Retriever passes, but for final mTICI 3 patients, this progressive decline only occurred after the 3 Stent Retriever passes [27]. This observation may suggest that the benefit of mTICI 3 recanalization is offset by the adverse effect of 3 Stent Retriever passes, beyond which the ultimate outcome is adversely affected. A single-center retrospective study showed that 3 Stent Retriever passes were an important predictor of prognosis [14]. Patients with 1 to 3 Stent Retriever passes had a higher rate of clinical good outcome ( $28.9 \%$ vs. $7.4 \%$; $\mathrm{P}=0.018)$ [13]. There is a significant correlation between the number of Stent Retriever passes and the good prognosis of acuteAIS. In patients with the same degree of recanalization, the fewer times of Stent Retriever passes experienced, the greater the possibility of good prognosis, and 3 times may be the best number of Stent Retriever passes for target vessel occlusion. These results needs to be further verified by high quality randomized controlled trial (RCT) tests.

\subsection{Factors Influencing the Number of Stent Retriever Passes}

At present, the number of Stent Retriever passes is closely related to the clinical outcomes and prognosis of patients with AIS, and there are still many problems that have not reached a unified understanding of the related factors that affect the number of Stent Retriever passes.

According to relevant studies, the closer the initial location of vascular occlusion was, the incidence of first pass recanalization (FPR) decreased gradually and became an independent predictor of FPR (internal carotid artery [ICA] terminal vs. middle cerebral artery [MCA]-M1 vs. MCA-M2, OR, 0.68; 95\% CI, 0.49 to 0.94; $\mathrm{P}=0.02$ ) [7]. Zaidat Oo et al. found that the independent predictors of FPR were the use of a balloon guided catheter and non-carotid terminal occlusion. In addition, the FPR group had a significantly higher proportion of women and over 80 years of age, and a lower incidence of ICA occlusion [26]. A. Filioglo et al. also found that the incidence of internal carotid artery occlusion was higher in patients with $\geq 5$ Stent Retriever passes, and the incidence of middle cerebral artery occlusion was higher in patients with $\leq 4$ Stent Retriever passes $(\mathrm{P}=0.005)$ [12].

Other studies have found that patients with lower clot burden score (CBS) need more times of Stent Retriever passes to achieve revascularization, and the number of operations in the process of thrombectomy depends on the efficiency of the equipment for revascularization and the thrombosis burden [15] [28]. Goyal $\mathrm{N}$ et al. found that the number of Stent Retriever passes required may be affected by intravenous thrombolysis (IVT) [29].

\section{Discussion}

EVT is the first-line treatment for AIS [30], and it is necessary to develop the best intravascular treatment strategy for the best EVT outcome. Current chal- 
lenges in this field focus on reducing recanalization time, optimizing patient selection, and evaluating the best technical approach. The number of Stent Retriever passes is closely related to the clinical outcome of EVT.

The number of Stent Retriever passes less than 3 times can improve the chance of vascular recanalization and is beneficial to the prognosis, while increasing the number of additional attempts on this basis is not beneficial and increases the incidence of related complications. In addition, each additional passes increased PTR by 15.9 minutes $(\mathrm{P}<0.001)$, while related studies have found that successful recanalization of the vessel within 125 minutes of PTR may benefit the patient's ultimate prognosis [8]. The benefits of recanalization are offset by the adverse effects of thrombectomy procedures, and the final outcome may be affected by the number of Stent Retriever passes.

However, in some cases, it is impossible to recanalization even after multiple Stent Retriever passes [8] [16] [31]. Another study found that, despite the need for more Stent Retriever passes and time, patients with multiple Stent Retriever passes who obtained recanalization had better clinical outcomes than patients without successful recanalization, and the most significant predictor of good prognosis was good recanalization of target vessels [3] [32]. A considerable number of patients can still achieve functional independence after 5 Stent Retriever passes [3]. Therefore, the strategy of EVT needs to be customized according to different patients. For some patients, it may not be necessary to limit the number of Stent Retriever passes, but the final good recanalization of the vessels should be the main goal. Therefore, the optimal number of Stent Retriever passes in patients who fail to achieve substantial recanalization is worthy of further study. Similarly, the effective indicators that can be screened out in relevant patients also need further verification.

There are many factors affecting the number of Stent Retriever passes, including the location of vascular occlusion, the origin and texture of the thrombus, vascular anatomy, bridging treatment, and even gender and age. In addition, Neurologists' different treatment concepts and experience preferences also make it more scientific and reasonable to make individualized treatment plans according to specific patients, imaging, characteristics of thrombosis and other relevant characteristic indicators. At present, studies on the reduction of thrombectomy times are devoted to the updating of thrombectomy materials, but little progress has been made recently, and further strengthening is needed in the future [33]. Each patient has a single optimal EVT strategy, so to what extent can patients finally achieve recanalization? If complete recanalization cannot be achieved, what is the maximum number of Stent Retriever passes required? What is the maximum number of Stent Retriever passes can withstand? Is there a more objective and effective indicator to screen and evaluate patients more accurately? These issues still need to be further studied and demonstrated by high-quality randomized controlled trials in order to further improve the effectiveness and safety of EVT for AIS and reduce repeated ineffective or even harmful endovascular procedures. 


\section{Conclusion}

It is necessary to avoid unplanned, additional attempts at EVT. The number of Stent Retriever passes has significant effects on the outcome of EVT of AIS in many aspects. How to better personalized EVT strategy is the focus of future research.

\section{Acknowledgements}

We thank all study participants and data collectors for their participation and cooperation. We would also like to thank the Cerebrovascular Disease Center of Gansu Provincial Hospital for its comprehensive cooperation and data support. We would like to thank Futian Tang (from Lanzhou University, China) for their advice on the English language version and revision of the final manuscript.

\section{Declarations}

\section{Funding}

This work was supported by the Lanzhou Talent Innovation and Entrepreneurship Project, China (2017-RC-57) and the Key Laboratory of Cerebrovascular Disease of Gansu Province, Gansu Provincial Hospital. The funders had no role in the study design, data collection, analysis, decision to publish, or preparation of the manuscript.

\section{Author Contributions}

All authors made a significant contribution to the work reported, whether in the conception, study design, execution, acquisition of data, analysis, and interpretation, or in all the following areas: drafting, revising, or critically reviewing the article; giving final approval of the version to be published; agreeing on the journal to which the article will be submitted; and agreeing to be accountable for all aspects of the work.

\section{Conflicts of Interest}

The authors declare no conflicts of interest regarding the publication of this paper.

\section{References}

[1] Pandian, J.D., Kalkonde, Y., Sebastian, I.A., Felix, C., Urimubenshi, G. and Bosch, J. (2020) Stroke Systems of Care in Low-Income and Middle-Income Countries: Challenges and Opportunities. Lancet, 396, 1443-1451. https://doi.org/10.1016/S0140-6736(20)31374-X

[2] Kang, D.H., Kim, B.M., Heo, J.H., Nam, H.S., Kim, Y.D., Hwang, Y.H., Kim, Y., Kim, D.J., Kim, J.W., Baek, J. and Kim, Y. (2020) Effects of First Pass Recanalization on Outcomes of Contact Aspiration Thrombectomy. Journal of NeuroInterventional Surgery, 12, 466-470. https://doi.org/10.1136/neurintsurg-2019-015221

[3] Filioglo, A., Cohen, J.E., Honig, A., Simaan, N., Gomori, J.M. and Leker, R.R. (2020) 
More than Five Stentriever Passes: Real Benefit or Futile Recanalization? Neuroradiology, 62, 1335-1340. https://doi.org/10.1007/s00234-020-02469-X

[4] Kharouba, R., Gavriliuc, P., Yaghmour, N.E., Gomori, J.M., Cohen, J.E. and Leker, R.R. (2019) Number of Stentriever Passes and Outcome after Thrombectomy in Stroke. Journal of Neuroradiology, 46, 327-330.

https://doi.org/10.1016/j.neurad.2019.03.014

[5] Goyal, M., Menon, B.K., van Zwam, W.H., Dippel, D.W., Mitchell, P.J., Demchuk, A.M., Davalos, A., Majoie, C.B., van der Lugt, A., de Miquel, M.A., Donnan, G.A., Roos, Y.B., Bonafe, A., Jahan, R., H. Diener, C., van den Berg, L.A., Levy, E.I., Berkhemer, O.A., Pereira, V.M., Rempel, J., Millan, M., Davis, S.M., Roy, D., Thornton, J., Roman, L.S., Ribo, M., Beumer, D., Stouch, B., Brown, S., Campbell, B.C., van Oostenbrugge, R.J., Saver, J.L., Hill, M.D. and Jovin, T.G. (2016) Endovascular Thrombectomy after Large-Vessel Ischaemic Stroke: A Meta-Analysis of Individual Patient Data from Five Randomised Trials. Lancet, 387, 1723-1731.

https://doi.org/10.1016/S0140-6736(16)00163-X

[6] Fransen, P.S., Berkhemer, O.A., Lingsma, H.F., Beumer, D., van den Berg, L.A., Yoo, A.J., Schonewille, W.J., Vos, J.A., Nederkoorn, P.J., Wermer, M.J., van Walderveen, M.A., Staals, J., Hofmeijer, J., van Oostayen, J.A., Lycklama, A.N.G., Boiten, J., Brouwer, P.A., Emmer, B.J., de Bruijn, S.F., van Dijk, L.C., Kappelle, L.J., Lo, R.H., van Dijk, E.J., de Vries, J., de Kort, P.L., van den Berg, J.S., van Hasselt, B.A., Aerden, L.A., Dallinga, R.J., Visser, M.C., Bot, J.C., Vroomen, P.C., Eshghi, O., Schreuder, T.H., Heijboer, R.J., Keizer, K., Tielbeek, A.V., den Hertog, H.M., Gerrits, D.G., van den Berg-Vos, R.M., Karas, G.B., Steyerberg, E.W., Flach, H.Z., Marquering, H.A., Sprengers, M.E., Jenniskens, S.F., Beenen, L.F., van den Berg, R., Koudstaal, P.J., van Zwam, W.H., Roos, Y.B., van Oostenbrugge, R.J., Majoie, C.B., van der Lugt, A. and Dippel, D.W. (2016) Time to Reperfusion and Treatment Effect for Acute Ischemic Stroke: A Randomized Clinical Trial. JAMA Neurology, 73, 190-196.

[7] García-Tornel, Á., Requena, M., Rubiera, M., Muchada, M., Pagola, J., Rodriguez-Luna, D., Deck, M., Juega, J., Rodríguez-Villatoro, N., Boned, S., Olivé-Gadea, M., Tomasello, A., Hernández, D., Molina, C.A. and Ribo, M. (2019) When to Stop. Stroke, 50, 1781-1788. https://doi.org/10.1161/STROKEAHA.119.025088

[8] Baek, J., Kim, B.M., Heo, J.H., Nam, H.S., Kim, Y.D., Park, H., Bang, O.Y., Yoo, J., Kim, D.J., Jeon, P., Baik, S.K., Suh, S.H., Lee, K., Kwak, H.S., Roh, H.G., Lee, Y., Kim, S.H., Ryu, C.W., Ihn, Y., Kim, B., Jeon, H., Kim, J.W., Byun, J.S., Suh, S., Park, J.J., Lee, W.J., Roh, J. and Shin, B. (2018) Number of Stent Retriever Passes Associated With Futile Recanalization in Acute Stroke. Stroke, 49, 2088-2095. https://doi.org/10.1161/STROKEAHA.118.021320

[9] Flottmann, F., Leischner, H., Broocks, G., Nawabi, J., Bernhardt, M., Faizy, T.D., Deb-Chatterji, M., Thomalla, G., Fiehler, J. and Brekenfeld, C. (2018) Recanalization Rate per Retrieval Attempt in Mechanical Thrombectomy for Acute Ischemic Stroke. Stroke, 49, 2523-2525. https://doi.org/10.1161/STROKEAHA.118.022737

[10] Loh, Y., Jahan, R., Liebeskind, D.S., Vinuela, F., Mcarthur, D.L., Shi, Z.S., Gonzalez, N.R., Duckwiler, G.R., Vespa, P.M., Starkman, S., Saver, J.L. and Tateshima, S. (2010) Recanalization Rates Decrease with Increasing Thrombectomy Attempts. American Journal of Neuroradiology, 31, 935-939. https://doi.org/10.3174/ajnr.A1958

[11] Angermaier, A., Michel, P., Khaw, A.V., Kirsch, M., Kessler, C. and Langner, S. (2016) Intravenous Thrombolysis and Passes of Thrombectomy as Predictors for Endovascular Revascularization in Ischemic Stroke. Journal of Stroke and Cerebrovascular Diseases, 25, 2488-2495. 
[12] Desai, S.M., Tonetti, D.A., Morrison, A.A., Gross, B.A., Jankowitz, B.T., Jovin, T.G. and Jadhav, A.P. (2020) Relationship between Reperfusion and Intracranial Hemorrhage after Thrombectomy. Journal of NeuroInterventional Surgery, 12, 448-453. https://doi.org/10.1136/neurintsurg-2019-015337

[13] Renú, A., Laredo, C., Tudela, R., Urra, X., Lopez-Rueda, A., Llull, L., Oleaga, L., Amaro, S. and Chamorro, Á. (2017) Brain Hemorrhage after Endovascular Reperfusion Therapy of Ischemic Stroke: A Threshold-Finding Whole-Brain Perfusion CT Study. Journal of Cerebral Blood Flow \& Metabolism, 37, 153-165. https://doi.org/10.1177/0271678X15621704

[14] Kalinin, M.N., Khasanova, D.R. and Ibatullin, M.M. (2017) The Hemorrhagic Transformation Index Score: A Prediction Tool in Middle Cerebral Artery Ischemic Stroke. BMC Neurology, 17, Article No. 177. https://doi.org/10.1186/s12883-017-0958-3

[15] Hao, Y., Yang, D., Wang, H., Zi, W., Zhang, M., Geng, Y., Zhou, Z., Wang, W., Xu, H., Tian, X., Lv, P., Liu, Y., Xiong, Y., Liu, X., Xu, G., Liu, C., Shi, Z., Zhang, J., Lin, H., Lin, M., Hu, Z., Deng, X., Wan, Y., Zhang, J., Shi, Z., Qu, M., Huang, X., Quan, T., Guan, S., Chen, L., Li, X., Wang, S., Yang, S., Liu, W., Wei, D., Wang, Z., Liu, X., Guo, F., Yang, S., Zheng, D., Wu, X., Zeng, Y., Tu, M., Jin, P., Liu, Y., Li, H., Fang, J. and Xiao, G. (2017) Predictors for Symptomatic Intracranial Hemorrhage After Endovascular Treatment of Acute Ischemic Stroke. Stroke, 48, 1203-1209. https://doi.org/10.1161/STROKEAHA.116.016368

[16] Bourcier, R., Saleme, S., Labreuche, J., Mazighi, M., Fahed, R., Blanc, R., Gory, B., Kyheng, M., Marnat, G., Bracard, S., Desal, H., Consoli, A., Piotin, M. and Lapergue, B. (2019) More than Three Passes of Stent Retriever Is an Independent Predictor of Parenchymal Hematoma in Acute Ischemic Stroke. Journal of NeuroInterventional Surgery, 11, 625-629. https://doi.org/10.1136/neurintsurg-2018-014380

[17] Pederson, J.M., Reierson, N.L., Hardy, N., Touchette, J.C., Medam, S., Barrett, A., Schmidt, M., Brinjikji, W., Kallmes, D.F. and Kallmes, K.M. (2021) Comparison of Balloon Guide Catheters and Standard Guide Catheters for Acute Ischemic Stroke: A Systematic Review and Meta-Analysis. World Neurosurgery, 154, 144-153.

[18] Qin, C., Shang, K., Xu, S.B., Wang, W., Zhang, Q. and Tian, D.S. (2018) Efficacy and Safety of Direct Aspiration versus Stent-Retriever for Recanalization in Acute Cerebral Infarction: A PRISMA-Compliant Systematic Review and Meta-Analysis. Medicine (Baltimore), 97, e12770. https://doi.org/10.1097/MD.0000000000012770

[19] Hassan, A.E., Kotta, H., Shariff, U., Preston, L., Tekle, W. and Qureshi, A. (2019) There Is No Association Between the Number of Stent Retriever Passes and the Incidence of Hemorrhagic Transformation for Patients Undergoing Mechanical Thrombectomy. Frontiers in Neurology, 10, Article No. 818.

https://doi.org/10.3389/fneur.2019.00818

[20] Khatri, P., Yeatts, S.D., Mazighi, M., Broderick, J.P., Liebeskind, D.S., Demchuk, A.M., Amarenco, P., Carrozzella, J., Spilker, J., Foster, L.D., Goyal, M., Hill, M.D., Palesch, Y.Y., Jauch, E.C., Haley, E.C., Vagal, A. and Tomsick, T.A. (2014) Time to Angiographic Reperfusion and Clinical Outcome after Acute Ischaemic Stroke: An Analysis of Data from the Interventional Management of Stroke (IMS III) Phase 3 Trial. Lancet Neurology, 13, 567-574. https://doi.org/10.1016/S1474-4422(14)70066-3

[21] Kleine, J.F., Wunderlich, S., Zimmer, C. and Kaesmacher, J. (2017) Time to Redefine Success? TICI 3 versus TICI 2b Recanalization in Middle Cerebral Artery Occlusion Treated with Thrombectomy. Journal of NeuroInterventional Surgery, 9, 117-121. https://doi.org/10.1136/neurintsurg-2015-012218

[22] Saver, J.L., Goyal, M., van der Lugt, A., Menon, B.K., Majoie, C.B.L.M., Dippel, 
D.W., Campbell, B.C., Nogueira, R.G., Demchuk, A.M., Tomasello, A., Cardona, P., Devlin, T.G., Frei, D.F., du Mesnil de Rochemont, R., Berkhemer, O.A., Jovin, T.G., Siddiqui, A.H., van Zwam, W.H., Davis, S.M., Castaño, C., Sapkota, B.L., Fransen, P.S., Molina, C., van Oostenbrugge, R.J., Chamorro, Á., Lingsma, H., Silver, F.L., Donnan, G.A., Shuaib, A., Brown, S., Stouch, B., Mitchell, P.J., Davalos, A., Roos, Y.B.W.E. and Hill, M.D. (2016) Time to Treatment With Endovascular Thrombectomy and Outcomes from Ischemic Stroke: A Meta-Analysis. JAMA, 316, 1279-1289. https://doi.org/10.1001/jama.2016.13647

[23] Mazighi, M., Chaudhry, S.A., Ribo, M., Khatri, P., Skoloudik, D., Mokin, M., Labreuche, J., Meseguer, E., Yeatts, S.D., Siddiqui, A.H., Broderick, J., Molina, C.A., Qureshi, A.I. and Amarenco, P. (2013) Impact of Onset-to-Reperfusion Time on Stroke Mortality: A Collaborative Pooled Analysis. Circulation, 127, 1980-1985. https://doi.org/10.1161/CIRCULATIONAHA.112.000311

[24] Goyal, M., Demchuk, A.M., Menon, B.K., Eesa, M., Rempel, J.L., Thornton, J., Roy, D., Jovin, T.G., Willinsky, R.A., Sapkota, B.L., Dowlatshahi, D., Frei, D.F., Kamal, N.R., Montanera, W.J., Poppe, A.Y., Ryckborst, K.J., Silver, F.L., Shuaib, A., Tampieri, D., Williams, D., Bang, O.Y., Baxter, B.W., Burns, P.A., Choe, H., Heo, J.H., Holmstedt, C.A., Jankowitz, B., Kelly, M., Linares, G., Mandzia, J.L., Shankar, J., Sohn, S.I., Swartz, R.H., Barber, P.A., Coutts, S.B., Smith, E.E., Morrish, W.F., Weill, A., Subramaniam, S., Mitha, A.P., Wong, J.H., Lowerison, M.W., Sajobi, T.T. and Hill, M.D. (2015) Randomized Assessment of Rapid Endovascular Treatment of Ischemic Stroke. New England Journal of Medicine, 372, 1019-1030. https://doi.org/10.1056/NEJMoa1414905

[25] Molina, C.A. (2010) Futile Recanalization in Mechanical Embolectomy Trials. Stroke, 41, 842-843. https://doi.org/10.1161/STROKEAHA.110.580266

[26] Zaidat, O.O., Castonguay, A.C., Linfante, I., Gupta, R., Martin, C.O., Holloway, W.E., Mueller-Kronast, N., English, J.D., Dabus, G., Malisch, T.W., Marden, F.A., Bozorgchami, H., Xavier, A., Rai, A.T., Froehler, M.T., Badruddin, A., Nguyen, T.N., Taqi, M.A., Abraham, M.G., Yoo, A.J., Janardhan, V., Shaltoni, H., Novakovic, R., Abou-Chebl, A., Chen, P.R., Britz, G.W., Sun, C.J., Bansal, V., Kaushal, R., Nanda, A. and Nogueira, R.G. (2018) First Pass Effect. Stroke, 49, 660-666. https://doi.org/10.1161/STROKEAHA.117.020315

[27] Seker, F., Pfaff, J., Wolf, M., Ringleb, P.A., Nagel, S., Schönenberger, S., Herweh, C., Möhlenbruch, M.A., Bendszus, M. and Pham, M. (2017) Correlation of Thrombectomy Maneuver Count with Recanalization Success and Clinical Outcome in $\mathrm{Pa}$ tients with Ischemic Stroke. American Journal of Neuroradiology, 38, 1368-1371.

[28] Tan, I.Y.L., Demchuk, A.M., Hopyan, J., Zhang, L., Gladstone, D., Wong, K., Martin, M., Symons, S.P., Fox, A.J. and Aviv, R.I. (2009) CT Angiography Clot Burden Score and Collateral Score: Correlation with Clinical and Radiologic Outcomes in Acute Middle Cerebral Artery Infarct. American Journal of Neuroradiology, 30, 525-531.

[29] Goyal, N., Tsivgoulis, G., Pandhi, A., Malhotra, K., Krishnan, R., Ishfaq, M.F., Krishnaiah, B., Nickele, C., Inoa-Acosta, V., Katsanos, A.H., Hoit, D., Elijovich, L., Alexandrov, A. and Arthur, A.S. (2019) Impact of Pretreatment with Intravenous Thrombolysis on Reperfusion Status in Acute Strokes Treated with Mechanical Thrombectomy. Journal of NeuroInterventional Surgery, 11, 1073-1079. https://doi.org/10.1136/neurintsurg-2019-014746

[30] Powers, W.J., Rabinstein, A.A., Ackerson, T., Adeoye, O.M., Bambakidis, N.C., Becker, K., Biller, J., Brown, M., Demaerschalk, B.M., Hoh, B., Jauch, E.C., Kidwell, C.S., Leslie-Mazwi, T.M., Ovbiagele, B., Scott, P.A., Sheth, K.N., Southerland, A.M., 
Summers, D.V. and Tirschwell, D.L. (2019) Guidelines for the Early Management of Patients With Acute Ischemic Stroke: 2019 Update to the 2018 Guidelines for the Early Management of Acute Ischemic Stroke: A Guideline for Healthcare Professionals From the American Heart Association/American Stroke Association. Stroke, 50, e344-e418. https://doi.org/10.1161/STR.0000000000000211

[31] Leischner, H., Flottmann, F., Hanning, U., Broocks, G., Faizy, T.D., Deb-Chatterji, M., Bernhardt, M., Brekenfeld, C., Buhk, J., Gellissen, S., Thomalla, G., Gerloff, C. and Fiehler, J. (2019) Reasons for Failed Endovascular Recanalization Attempts in Stroke Patients. Journal of NeuroInterventional Surgery, 11, 439-442.

https://doi.org/10.1136/neurintsurg-2018-014060

[32] Tonetti, D.A., Desai, S.M., Casillo, S., Stone, J., Brown, M., Jankowitz, B., Jovin, T.G., Gross, B.A. and Jadhav, A. (2020) Successful Reperfusion, Rather than Number of Passes, Predicts Clinical Outcome after Mechanical Thrombectomy. Journal of NeuroInterventional Surgery, 12, 548-551.

https://doi.org/10.1136/neurintsurg-2019-015330

[33] Liu, Y., Gebrezgiabhier, D., Zheng, Y., Shih, A.J., Chaudhary, N., Pandey, A.S., Larco, J., Madhani, S.I., Abbasi, M., Shahid, A.H., Quinton, R.A., Kadirvel, R., Brinjikji, W., Kallmes, D.F. and Savastano, L.E. (2022) Arterial Collapse during Thrombectomy for Stroke: Clinical Evidence and Experimental Findings in Human Brains and in Vivo Models. American Journal of Neuroradiology, 43, 251-257. 